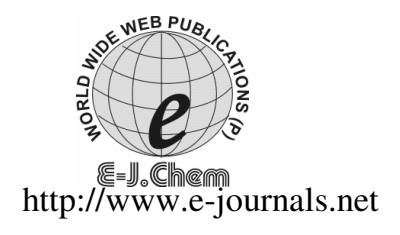

ISSN: 0973-4945; CODEN ECJHAO

E-Journal of Chemistry 2011, 8(1), 131-148

\title{
Determination of Mesalamine Related Impurities from Drug Product by Reversed Phase Validated UPLC Method
}

\author{
TRIVEDI RAKSHIT KANUBHAI ${ }^{\S *}$, PATEL MUKESH C and KHARKAR AMIT R ${ }^{\S}$ \\ ${ }^{\S}$ Analytical Research and Development \\ Integrated Product Development, Dr. Reddy's Laboratories Ltd. \\ Bachupally, Hyderabad-500 072, India \\ P.S. Science and H.D. Patel Arts College, S.V. Campus, Kadi-382 715, Gujarat, India \\ triveditr@yahoo.com
}

Received 5 June 2010; Accepted 24 August 2010

\begin{abstract}
In the present study gradient reversed-phase UPLC method was developed for simultaneous determination and separation of impurities and degradation products from drug product. The chromatographic separation was performed on acquity UPLC BEH C18 column (50 mm x $2.1 \mathrm{~mm}, 1.7 \mu \mathrm{m})$ using gradient elution. Other UPLC parameters which were optimised are flow rate, $0.7 \mathrm{~mL} / \mathrm{min}$; detection wavelength, $220 \mathrm{~nm}$; column oven temperature, $40{ }^{\circ} \mathrm{C}$; and injection volume $7 \mu \mathrm{L}$. Stability indicating capability was established by forced degradation experiments and separation of known degradation products. The method was validated as per International Conference on Harmonization ( $\mathrm{ICH})$ guideline. For all impurities and mesalamine, LOQ (limit of quantification) value was found precise with RSD (related standard daviation) of less than $2.0 \%$. In essence, the present study provides an improved low detection limit and lower run time for evaluation of pharmaceutical quality of mesalamine delayed-release formulation. Moreover, the developed method was successfully applied for quantification of impurities and degradation products in mesalamine delayed-release formulation. The same method can also be used for determination of related substances from mesalamine drug substance.
\end{abstract}

Keywords: Mesalamine, 5-Aminosalicylic acid, Stability indicating, UPLC, Validation.

\section{Introduction}

Mesalamine (5-aminosalicylic acid, 5-ASA), the therapeutically active moiety of sulfasalazine ${ }^{1-3}$ is routinely employed in the treatment of inflammatory bowel disease, that is ulcerative colitis and Crohn's disease. Various types of formulations are available for the mesalamine ${ }^{4}$

Orally administrated mesalamine is rapidly and almost completely absorbed from the small intestine $^{5-7}$. Formulations able to deliver the intact drug to the lower intestine are nowadays successfully used ${ }^{8,9}$. The purity evaluation of mesalamine in drug product by determination of related substances would be a first step in examination of the safety and quality of the drug product. Chemical structures and UV spectrums of mesalamine and its six impurities are shown 
in Figure 1. Mesalamine drug profile ${ }^{10}$ and degradation mechanism in aqueous solution was reported $^{11}$. Several articles for mesalamine metabolism ${ }^{12,13}$ and its determination by HPLC ${ }^{14-16}$ and HPLC-ESI-MS/MS ${ }^{17}$ has been reported. Estimation of mesalamine and its metabolites in plasma and urine by HPLC $^{18-20}$ and by fluorescence detector ${ }^{21}$ are also reported. Mesalamine HPLC determination in rectal tissue biopsies ${ }^{22}$ and endoscopic intestinal biopsy in human has been reported ${ }^{23}$. Identification of unknown impurity in mesalamine was also reported ${ }^{24,25}$.

Mesalamine protects against colorectal cancer in inflammatory bowel disease $\mathrm{e}^{26}$. HPLC determination of mesalamine and related impurities using ion-pairing reagent ${ }^{27}$ and by simple liquid chromatography ${ }^{28}$ has been reported. Mesalamine formulation determination by spectrophotometric $^{29}$, by HPLC and ultraviolate ${ }^{30}$ and by differential pulse voltammetry was reported ${ }^{31}$. Determination of mesalamine and its related impurity by micellar electrokinetic capillary chromatography has been reported ${ }^{32}$. Determination of mesalamine related impurities by micellar electrokinetic chromatography with an ion-pair reagent was reported ${ }^{33}$. Mesalamine determination in pharmaceutical dosage forms by HPLC, DPPH and nitrosation was also reported ${ }^{34}$.

Literatures survey revealed that the mesalamine drug substance is official in US Pharmacopeia $^{37}$ as well as in British Pharmacopoeia ${ }^{38}$. Mesalamine extended release capsules ${ }^{35}$ and mesalamine delayed-release tablets ${ }^{36}$, formulation is also official in US Pharmacopoeia. In pharmacopeia method (mesalamine delayed-release tablets), requirement of resolution (system suitability) in between salicylic acid, mesalamine and 3-aminosalicylic acid is not less than 2 . This resolution requirement (system suitability) is very low for the low ppm solution. In this method total run time, solution stability, impurities RRT (related retention time) and its order of elution for all impurities also not mentioned. Further, mesalamine delayed-release tablet USP monograph having unknown single max limit $0.5 \%$ with the area percent method. Now a day determination of Genotoxic and Carcinogenic Impurities (may be available in formulation as an unknown) in drug substances and product is the new approach from the regulatory agency ${ }^{41}$. Mesalamine delay release formulation having a higher amount of drug substance (total daily intake $1.2 \mathrm{~g} /$ day), below the qualification threshold, no investigation is required (intake is up to $2 \mathrm{~g}$ /day), although impurities at levels above $1000 \mathrm{ppm}$ (or $1 \mathrm{mg} /$ day) are expected, at the least, to be identified ${ }^{42}$. Subsequent guidance from the U.S. Food and Drug Administration (USFDA $)^{41}$ conform that the ICH thresholds may not be acceptable for carcinogenic impurities (may be unknown in drug substances). To control and determination of the unknown impurity in drug product at lower level will help to reduce the risk of carcinogenic.

So, determination of related substances would be a first step in examination of the safety and quality of the drug product. As per new approach related impurities/degradation products/unknown impurities RRT and good amount of resolution between all related substances in the drug product analytical method (with the low limit determination capability) is the first step to measure the quality of drug product.

Comprehensive literatures for measure the quality of mesalamine delayed-release product by HPLC have long run time, limited solution stability, less efficiency $(\mathrm{N})$, higher limit for unknown single maximum impurity, lack of related retention time for all impurities and less resolution, as such there is lack of a suitable procedure for the quantification and estimation for them. Therefore, the aim of the present work was to develop and validate a simple, precise, accurate, short runtime and specific method for the quantification and separation of 5-ASA and its impurities/degradation product by reversed-phase UPLC method, in mesalamine delayed-release formulation.

Moreover, analytical column with sub 2-micron particle size technology was explored for better chromatography. Working concentration and RRT for all related substances was mentioned in Table 1 . 
Table 1. Name of the impurities, working concentration (in $\%$ and $\mu \mathrm{g} / \mathrm{mL}$ ) and related retention time (RRT) with respect to mesalamine (5-ASA) are as follow.

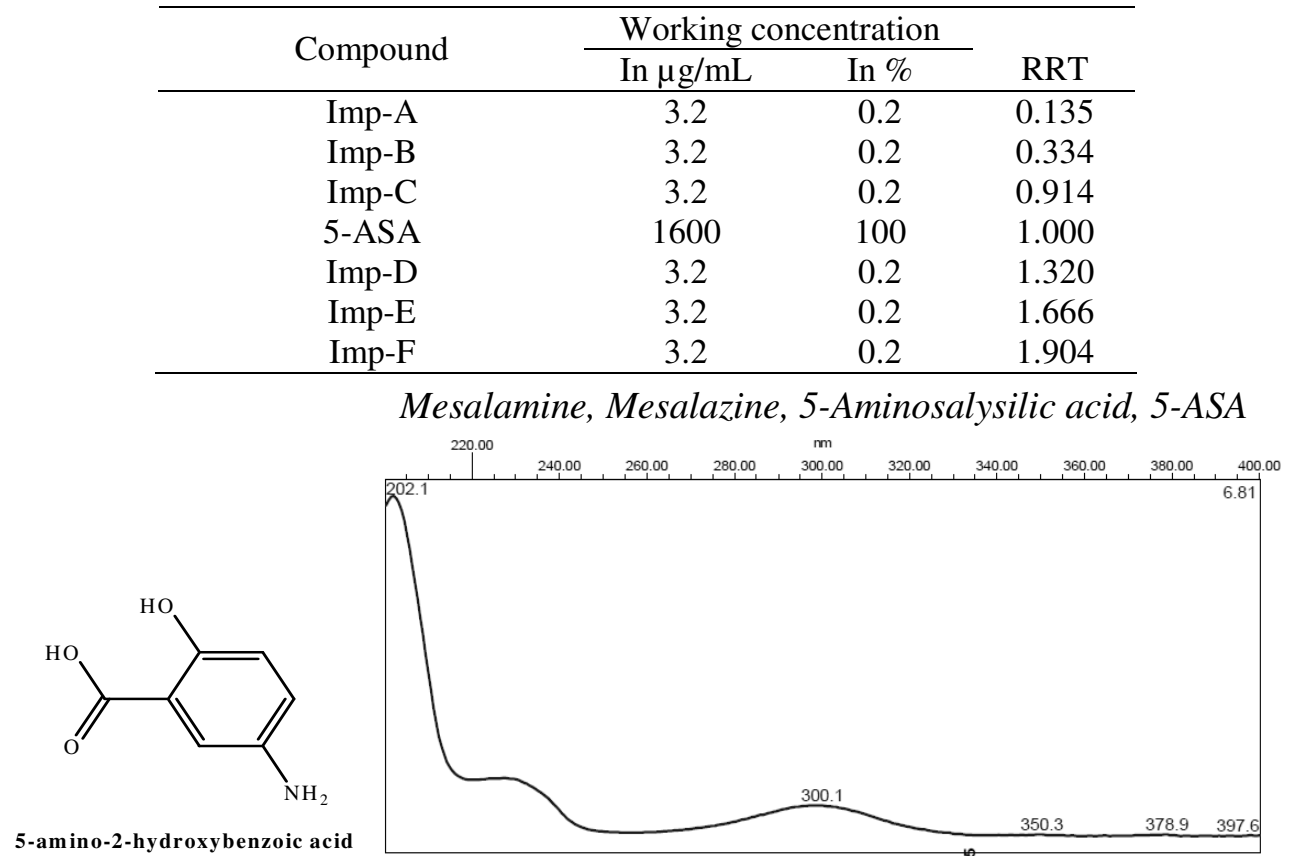

2,5-Dihydroxybenzoic acid; [Impurity-A]
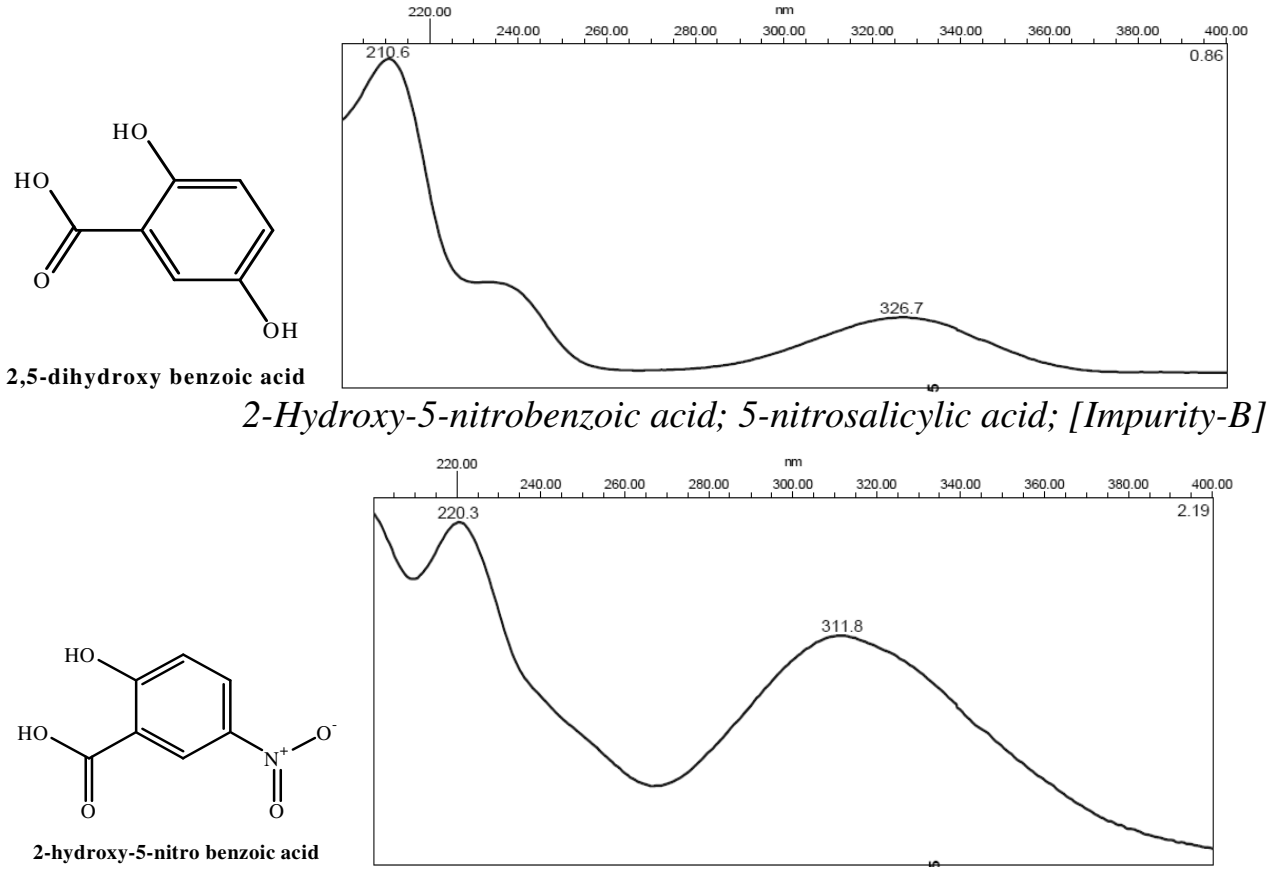


\section{2-Hydroxybenzoic acid; Salicylic acid; [Impurity-C]}

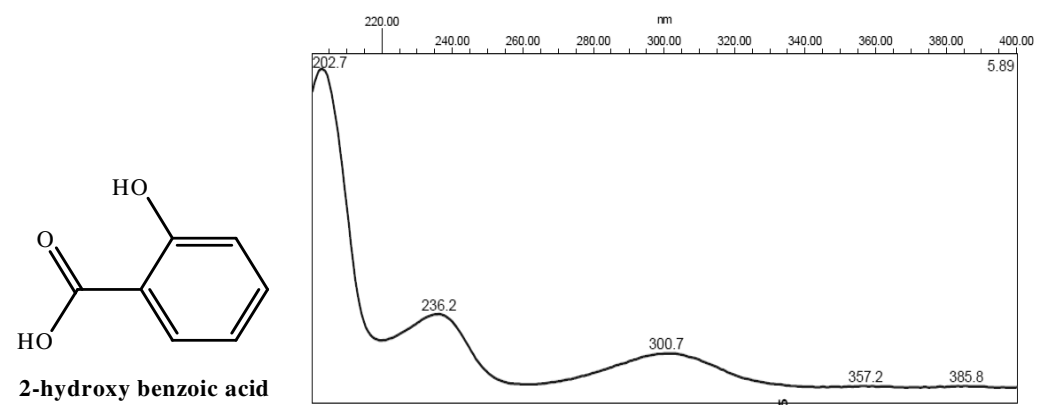

3-amino-2-hydroxybenzoic acid; 3-aminosalicylic acid; [Impurity-D]
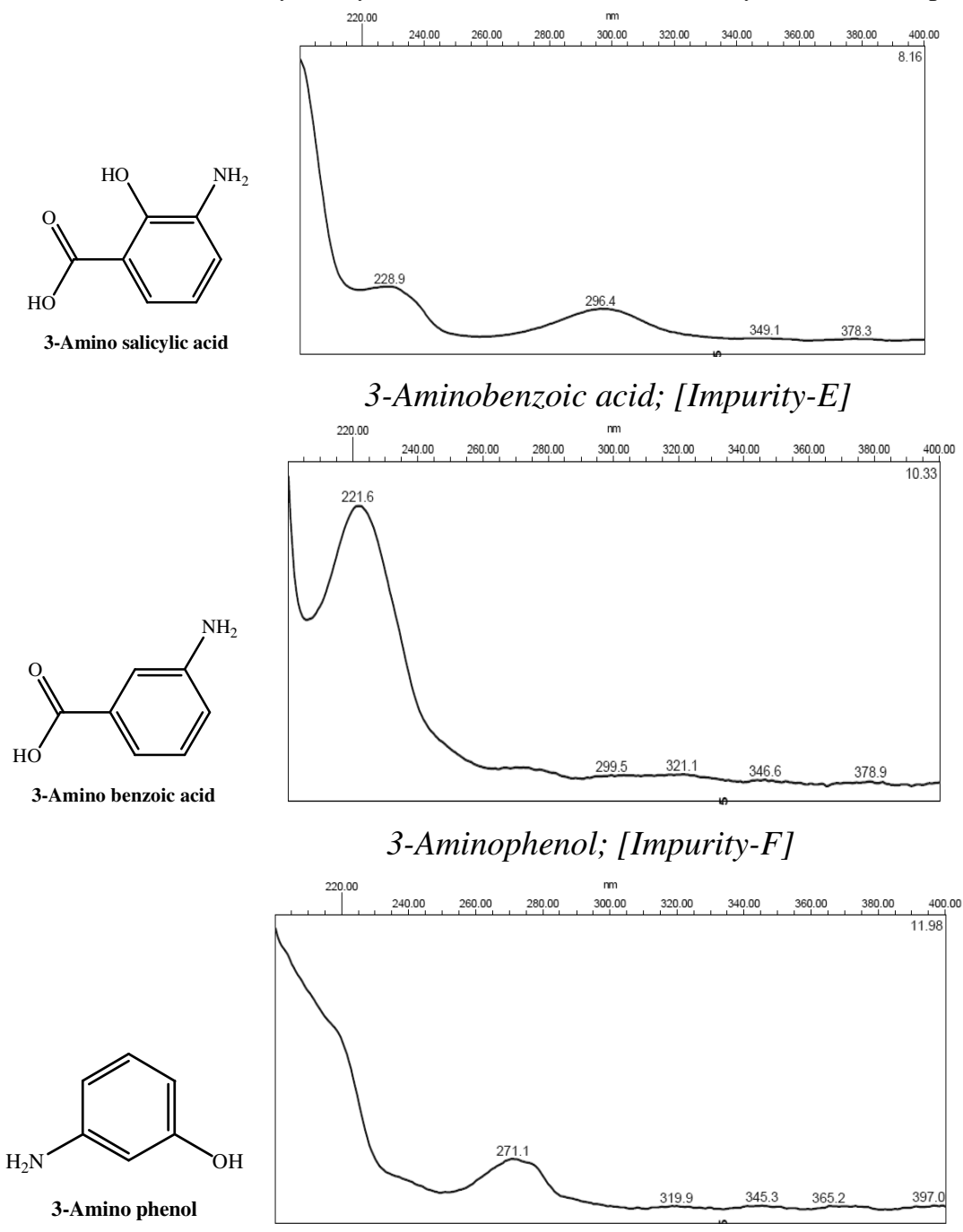

Figure 1. Chemical structures and UV spectrums of mesalamine and its six impurities 


\section{Experimental}

Mesalamine delayed-release tablets, placebo of mesalamine tablets, mesalamine [5-ASA] USP reference standard, impurity-A to F, were provided by Dr. Reddy's laboratories Ltd., Hyderabad. HPLC grade acetonitrile and methanol were obtained from J.T.Baker (NJ., USA). HPLC grade 1-octane sulphonic acid sodium salt was obtained from RANKEM (RFCL Ltd., Delhi). Dipotassium hydrogen orthophosphate purified, potassium dihydrogen orthophosphate purified, GR grade orhtophosphoric acid and GR grade hydrochloric acid were obtained from Merck (Mumbai, India). $0.2 \mu \mathrm{m}$ nylon 66 membrane filter and $0.2 \mu \mathrm{m}$ nylon syringe filter used was a product of Pall life science limited (India). $0.2 \mu \mathrm{m}$ PVDF syringe filter used was manufactured by Millipore (India). High purity water was generated by using Milli-Q Plus water purification system (Millipore, Milford, MA, USA). All experiments were performed using 'A' class volumetric glassware and GLP compliance analytical laboratory.

\section{Equipment}

Cintex digital water bath was used for specificity study. Photo stability studies were carried out in a photo-stability chamber (Sanyo, Leicestershire, UK). Thermal stability studies were performed in a dry air oven (Cintex, Mumbai, India).

\section{Buffer preparation}

pH 2.2 buffer preparation: $1.36 \mathrm{~g}$ of potassium dihydrogen orthophosphate and $5.5 \mathrm{~g}$ of 1 octane sulphonic acid sodium salt was dissolved in $890 \mathrm{~mL}$ of Milli-Q water. The $\mathrm{pH}$ of this solution was adjusted to 2.2 with orthophosphoric acid and then filtered through $0.2 \mu \mathrm{m}$ nylon 66 membrane filter.

pH 6.0 buffer preparation: $1.74 \mathrm{~g}$ of dipotassium hydrogen orthophosphate and $5.5 \mathrm{~g}$ of 1 octane sulphonic acid sodium salt was dissolved in $890 \mathrm{~mL}$ of Milli-Q water. The $\mathrm{pH}$ of this solution was adjusted to 6.0 with orthophosphoric acid and then filtered through $0.2 \mu \mathrm{m}$ nylon 66 membrane filter. Bench top stability at room temperature for the both buffer preparation was found stable with respect to $\mathrm{pH}$ and visual clarity up to $48 \mathrm{~h}$.

\section{Diluent preparation}

Diluent-1: $1 \mathrm{~N}$ hydrochloric acid was used.

Diluent-2: $1.36 \mathrm{~g}$ of potassium dihydrogen orthophosphate and $2.2 \mathrm{~g}$ of 1-octane sulphonic acid sodium salt were dissolved in $890 \mathrm{~mL}$ of Milli-Q water. The $\mathrm{pH}$ of this solution was adjusted to 2.2 with orthophosphoric acid. Adjusted $\mathrm{pH}$ (2.2) buffer, methanol and acetonitrile were mixed well in the ratio of 890:80:30 (v/v/v) respectively.

\section{Chromatographic system}

Analyses were performed on Acquity UPLC ${ }^{\mathrm{TM}}$ system (Waters, Milford, USA), consisting of a binary solvent manager, sample manager and PDA (photo diode array) detector. System control, data collection and data processing were accomplished using Waters Empower- $2^{\mathrm{TM}}$ chromatography data software. The chromatographic condition was optimised using Acquity UPLC BEH C18 $(50 \mathrm{~mm} \times 2.1 \mathrm{~mm}, 1.7 \mu \mathrm{m})$ column. The buffer $\mathrm{pH} 2.2$ was used as a mobile phase-A (M.P.-A). Mobile phase-B (M.P.-B) was a mixture of buffer pH 6.0, methanol and acetonitrile in the ratio of 890:80:30 (v/v/v) respectively. Mobile phase-A and mobile phase-B was filtered through $0.2 \mu \mathrm{m}$ nylon membrane filter and degassed under vacuum prior to use. The separation of all impurities was achieved by gradient elution using M.P.-A and M.P.-B. The finally selected and optimized conditions were as follows: injection volume $7 \mu \mathrm{L}$, gradient elution (Table 2), at a flow rate of $0.7 \mathrm{~mL} / \mathrm{min}$ at $40{ }^{\circ} \mathrm{C}$ (column oven) temperature, detection wavelength $220 \mathrm{~nm}$. The stress degraded samples and the solution stability samples were analyzed using a PDA detector covering the range of 200-400 nm. 
Table 2. Gradients program for elution of 5-ASA and all impurities

\begin{tabular}{ccccc}
\hline Time, min & Flow rate, $\mathrm{mL} / \mathrm{min}$ & \% M.P.-A & \% M.P.-B & Gradient curve \\
\hline Initial & 0.7 & 90 & 10 & Isocratic \\
3 & 0.7 & 90 & 10 & Isocratic \\
13 & 0.7 & 10 & 90 & Linear \\
13.1 & 0.7 & 90 & 10 & Isocratic \\
15 & 0.7 & 90 & 10 & Equilibration \\
\hline
\end{tabular}

System suitability solution preparation

$1 \mathrm{mg}$ of 2-hydroxy benzoic acid (salicylic acid), $1 \mathrm{mg}$ of 5-ASA and $1 \mathrm{mg}$ of 3-amino salicylic acid standard was taken in $100 \mathrm{~mL}$ volumetric flask. About $6 \mathrm{~mL}$ of diluent-1 was added to this volumetric flask and sonicated in an ultrasonic bath for $10 \mathrm{~min}$. This solution was then diluted up to the mark with diluent- 2 and was mixed well. Three millilitres of this solution was transferred into $10 \mathrm{~mL}$ volumetric flask and diluted up to the mark with diluent-2 and was mixed well.

\section{Standard solution preparation}

About $32 \mathrm{mg}$ of 5-ASA working standard was taken into $100 \mathrm{~mL}$ volumetric flask, then added $6 \mathrm{~mL}$ of diluent- 1 and dissolved it by 10 minutes sonication. This solution was then diluted to the mark with diluent- 2 and was mixed well. Two millilitres of this solution was transferred into $200 \mathrm{~mL}$ volumetric flask and diluted up to the mark with diluent- 2 and was mixed well.

\section{Sample solution preparation}

Twenty tablets were crushed to fine powder. An accurately weighed portion of the powder equivalent to $400 \mathrm{mg}$ of mesalamine was taken into $250 \mathrm{~mL}$ volumetric flask. About $15 \mathrm{~mL}$ of diluent- 1 was added to this volumetric flask and sonicated in an ultrasonic bath for 10 minutes. This solution was then diluted up to the mark with diluent-2, mixed well. It was then filtered through $0.2 \mu \mathrm{m}$ PVDF syringe filter and the filtrate was collected after discarding first few millilitres.

\section{Placebo solution preparation}

Tablets placebo powder was taken into $250 \mathrm{~mL}$ volumetric flask. About $15 \mathrm{~mL}$ of diluent- 1 was added to this volumetric flask and sonicated in an ultrasonic bath for 10 minutes. This solution was then diluted up to the mark with diluent-2, mixed well. It was then filtered through $0.2 \mu \mathrm{m}$ PVDF syringe filter and the filtrate was collected after discarding first few millilitres.

\section{Method validation}

The proposed method was validated as per ICH guidelines ${ }^{39}$.

\section{System suitability}

System suitability parameters were measured so as to verify the system performance. In the system suitability solution chromatogram resolution between salicylic acid, mesalamine and 3 -aminosalicylic acid was measured. The similarity factor for the peak of mesalamine in duplicate standard preparation was measured. In the standard preparation theoretical plates and tailing factor for mesalamine peak was measured. Percentage related standard deviation for the peak areas of mesalamine for six replicate (standard solution) injections was also measured. All these system suitability parameters covered the system, method and column performance.

\section{Specificity}

Specificity is the ability of the method to measure the analyte response in the presence of its potential impurities ${ }^{39,40}$. Forced degradation studies were performed to demonstrate selectivity and stability indicating capability of the proposed method. The sample solution was exposed to 
acidic condition $\left(2 \mathrm{~N} \mathrm{HCl}, 60{ }^{\circ} \mathrm{C}, 6 \mathrm{~h}\right)$, alkaline condition $\left(1 \mathrm{~N} \mathrm{NaOH}, 60{ }^{\circ} \mathrm{C}, 1 \mathrm{~h}\right)$, strong oxidizing $\left(6 \% \mathrm{H}_{2} \mathrm{O}_{2}\right.$, bench top for $2 \mathrm{~h}$ ), Hydrolysis (water, $\left.60{ }^{\circ} \mathrm{C}, 2 \mathrm{~h}\right)$. The powdered sample of tablets was exposed to UV light (short and longer wavelengths, 7 days), dry heat $\left(105^{\circ} \mathrm{C}\right.$, $12 \mathrm{~h}$ ), humidity $\left(25^{\circ} \mathrm{C}, 90 \% \mathrm{RH}, 7\right.$ days) degradation conditions. Also, placebo of the tablets was exposed to above all stress conditions to identify the source of degradation peak. The entire exposed samples were analyzed by the proposed method with PDA detector.

\section{Precision}

The precision of the related substances method verified by repeatability and by intermediate precision. Precision was investigated using sample preparation procedure for six real samples (with spiked impurities in known concentration level) of tablets and analyzing by proposed method. Intermediate precision study was performed with different column, different instrument, and different day by another analyst. Precision was also performed at LOQ (in placebo), at $100 \%$ and $150 \%$ of specification limit level. The mean of percentage impurity $(\mathrm{n}=6)$ and the percentage relative standard deviation was also calculated for all substances.

\section{Accuracy}

To confirm the accuracy of the proposed method, recovery experiments were carried out by standard addition technique. Four different levels (LOQ, 50\%, 100\% and 150\%) of impurities standards were added to pre-analyzed tablet samples in triplicate. Four different levels (LOQ, $50 \%, 100 \%$ and $150 \%$ ) of mesalamine standard were added to pre-analyzed placebo samples in triplicate. The percentage recoveries of mesalamine and impurities at each level and each triplicate were determined. The mean of percentage recoveries was calculated.

\section{Limit of detection (LOD) and Limit of quantification (LOQ)}

The LOD and LOQ of mesalamine and all six impurities were determined (in placebo solution) by using signal to noise approach as defined in International Conference on Harmonization (ICH) guideline $\mathrm{e}^{39,40}$. Increasingly dilute solution of drug and each impurity was injected into the chromatograph and signal to noise $(\mathrm{S} / \mathrm{N})$ ratio was calculated at each concentration.

\section{Linearity}

Linearity was demonstrated from LOQ to $250 \%$ of working concentration by using minimum seven calibration levels for the mesalamine compound and all impurity standards. The method of linear regression was used for data evaluation. Peak area of compound was plotted against respective concentrations. Linearity was described by regression equation, correlation coefficient and Y-intercept bias.

\section{Robustness}

The robustness as a measure of method capacity to remain unaffected by small, but deliberate changes in chromatographic conditions was studies by testing influence of small changes in flow rate $( \pm 0.05 \mathrm{~mL} / \mathrm{min})$, change in column oven temperature $\left(38{ }^{\circ} \mathrm{C}\right.$ to $\left.42{ }^{\circ} \mathrm{C}\right)$ and change in $\mathrm{pH}$ of M.P.-A (pH 2.1 to $\mathrm{pH} 2.3$ ). Measured the system suitability criteria for all the above experiment and compared the related retention time for all the impurities with the initial RRT.

\section{Stability of standard and sample preparation}

Stability of standard and sample solution was established by storage of sample solution (duplicate preparation) and standard solution at ambient temperature for $24 \mathrm{~h}$. Sample solution stability was demonstrated by spiking impurity standards in pre-analyzed tablet sample. Standard and sample solutions were re-analyzed after $12 \mathrm{~h}$ and after $24 \mathrm{~h}$. For sample solution, percentage difference in impurities was calculated against fresh injected sample solution. Percentage RSD was calculated for standard preparation. 


\section{Filter compatibility}

Filter compatibility was performed for nylon $0.2 \mu \mathrm{m}$ syringe filter (Pall Life sciences) and PVDF $0.2 \mu \mathrm{m}$ syringe filter (Millipore). To confirm the filter compatibility in proposed method, filtration recovery experiments were carried out by sample filtration technique. The working concentration level impurities standard was added to pre-analyzed tablet sample in duplicate. Spiked impurities samples was filter through both syringe filters and percentage difference was calculated against centrifuged sample.

\section{Results and Discussion}

\section{Method development}

The important criteria for development of successful RP-UPLC method for determination of mesalamine related substances in delayed-release tablets were: the method should be able to determine all impurities of the drug in single run with the good amount of resolution and it should be accurate, reproducible, robust, stability indicating, free from interference (blank/ placebo/ other unknown degradation product) and straightforward enough for routine use in quality control laboratory.

To develop the stability indicating method, first the retention behaviour of these all compounds with change in percentage of organic solvent (acetonitrile and methanol) and with change in buffer substances and change in $\mathrm{pH}$ of buffer was studied on Waters Acquity $\mathrm{BEH}$ C18 column (50 mm x $2.1 \mathrm{~mm}, 1.7 \mu \mathrm{m})$. 1-Octane sulphonic acid ion pair reagent was used in buffer preparation to improve the resolution and avoid the other substances co elution at same retention time in RP chromatography. The buffer $\mathrm{pH} 2.2$ for M.P.-A was found more appropriate for robust resolution, peak shape and RRT performance of all the interested substances. The final gradient run was chosen with regards to the peak resolution and analysis time as well. The gradient program is given in Table 2 . The flow rate of $0.7 \mathrm{~mL} / \mathrm{min}$ was optimized with regard to the back pressure and analysis time as well. Diluents concentration was optimized to improve the solution stability and peak shape. Detection wavelength $220 \mathrm{~nm}$ was selected for mesalamine and its related substances due to higher detector response at this wavelength. Thus, determination of impurities was possible in single run.

\section{Analytical parameters and validation}

After satisfactory development of method it was subjected to method validation as per ICH guideline $^{39}$. The method was validated to demonstrate that it is suitable for its intended purpose by the standard procedure to evaluate adequate validation characteristics (system suitability, accuracy, precision, linearity, robustness, ruggedness, solution stability, LOD and LOQ, filter compatibility and stability indicating capability).

\section{System suitability}

The percentage RSD of mesalamine area count of six replicate injections was below $2.0 \%$. Low values of \% RSD of replicate injections indicate that the system is precise. Result of other system suitability parameters such as resolution, theoretical plates, tailing factor and similarity factor (between two standard preparations) are presented in Table 3. As seen from this data, the acceptable system suitability parameters would be: related standard deviation of replicate injections is not more than $2.0 \%$, resolution between salicylic acid and 5-ASA is not less than 3.0, resolution between 5-ASA and 3-aminosalicylic acid is not less than 6.0, theoretical plates for 5-ASA is not less than 10000, tailing factor for 5-ASA is not more than 1.5 and similarity factor (between two standard preparations) is not less than 0.95 and not more than 1.05. Results of system suitability parameters from different studies are presented in Table 3. Overlay chromatograms of replicate standard injection are presented in Figure 2. 


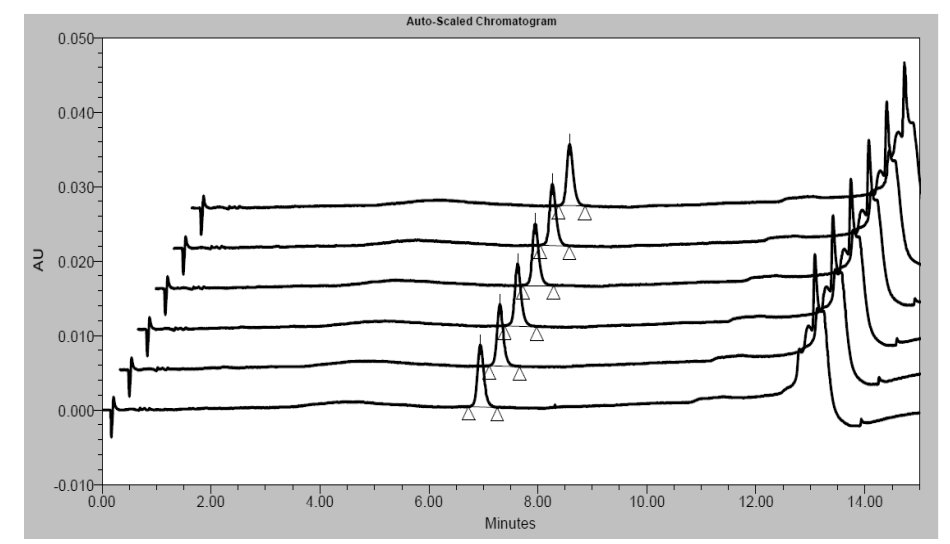

Figure 2. Overlay chromatograms of replicate standard injections

Table 3. System suitability results (precision, intermediate precision and robustness)

\begin{tabular}{|c|c|c|c|c|c|c|}
\hline Condition & $\begin{array}{l}\text { Resolution } \\
\text { between } \\
\text { Imp-C and } \\
5-A S A\end{array}$ & $\begin{array}{c}\text { Resolution } \\
\text { between } \\
5-A S A \\
\text { and Imp-D }\end{array}$ & $\begin{array}{c}\text { Theoretic } \\
\text { plates for } \\
\text { ASA }\end{array}$ & $\begin{array}{l}\text { Tailing } \\
\text { - factor for } \\
\text { 5-ASA }\end{array}$ & $\begin{array}{l}\text { Similarity } \\
\text { factor } \\
\text { between two } \\
\text { Standard }\end{array}$ & $\begin{array}{c}\% \text { RSD } \\
\text { of } \\
\text { Standard } \\
\text { Area }\end{array}$ \\
\hline Precision & 3.89 & 6.21 & 15416 & 1.25 & 0.97 & 0.5 \\
\hline $\begin{array}{l}\text { Intermediate } \\
\text { Precision }\end{array}$ & 4.11 & 6.89 & 14434 & 0.85 & 1.02 & 0.9 \\
\hline $\begin{array}{l}\text { At } 0.65 \mathrm{~mL} / \mathrm{min} \\
\text { flow rate }\end{array}$ & 3.73 & 6.54 & 14821 & 0.81 & 1.03 & 1.1 \\
\hline $\begin{array}{l}\text { At } 0.75 \mathrm{~mL} / \mathrm{min} \\
\text { flow rate }\end{array}$ & 3.74 & 6.57 & 14438 & 0.82 & 0.99 & 0.7 \\
\hline $\begin{array}{l}\text { At } 38^{\circ} \mathrm{C} \text { Column } \\
\text { oven temp. }\end{array}$ & 3.74 & 6.52 & 15403 & 0.83 & 1.01 & 0.5 \\
\hline $\begin{array}{l}\text { At } 42^{\circ} \mathrm{C} \text { Column } \\
\text { oven temp. }\end{array}$ & 3.79 & 6.58 & 14262 & 0.80 & 1.03 & 0.9 \\
\hline M.P.-A pH 2.1 & 3.82 & 6.63 & 14985 & 0.81 & 0.98 & 0.8 \\
\hline M.P.-A pH 2.3 & 3.83 & 6.60 & 15050 & 0.81 & 0.97 & 0.7 \\
\hline
\end{tabular}

\section{Specificity}

Typical overlaid chromatograms are presented in Figure 3 and 4, which shows separation of individual compounds and also shows that there is no any interferences at the RT (retention time) of individual compound due to blank and placebo. Chromatograms of base and peroxide degraded (with its 3D plot and purity plot) tablet samples are presented in Figure 5 and 6 respectively. Mesalamine was found to be stable under acid, heat, humidity, and light degradation condition. Further, spectra of unknown degradation products in tablet sample were similar to that of unknown degradation products of individual standards eluting at respective retention time. Also spectra of known impurities in degraded tablet sample were similar to its respective impurity standard substance, indicating that there was no co-elution of unknown degradation peak at retention times of respective known impurities. Peak due to mesalamine was investigated for spectral purity in the chromatogram of all exposed samples and found spectrally pure. The max plot of chromatograms degradation samples was also checked to ensure that no degradation peak is missed due to use of wavelength of $220 \mathrm{~nm}$. Therefore, the method is specific and suitable for routine work. The results of forced degradation study are given in Table 4 . 
Table 4. Forced degradation data and purity results of mesalamine (5-ASA)

\begin{tabular}{lcc}
\hline \multicolumn{1}{c}{ Stress condition } & 5-ASA & \multirow{2}{*}{ \% Degradation } \\
\cline { 2 - 2 } & Purity flag & \\
\hline Refluxed with $2 \mathrm{~N} \mathrm{HCl}$ solution at $60{ }^{\circ} \mathrm{C}$ for $6 \mathrm{~h}$. & No & 0.33 \\
Refluxed with $1 \mathrm{~N} \mathrm{NaOH}$ solution at $60{ }^{\circ} \mathrm{C}$ for $1 \mathrm{~h}$. & No & 5.05 \\
$6 \% \mathrm{H}_{2} \mathrm{O}_{2}$ solution bench top for $2 \mathrm{~h}$. & No & 4.30 \\
Refluxed with water at $60{ }^{\circ} \mathrm{C}$ for $2 \mathrm{~h}$. & No & 0.22 \\
Exposed to $\mathrm{UV} \mathrm{light.}$ & No & 0.35 \\
Dry heated at $105^{\circ} \mathrm{C}$ for about $12 \mathrm{~h}$. & No & 0.52 \\
Exposed to humidity $\left(25^{\circ} \mathrm{C}, 90 \% \mathrm{RH}\right)$ about 7 days. & No & 0.18 \\
\hline
\end{tabular}
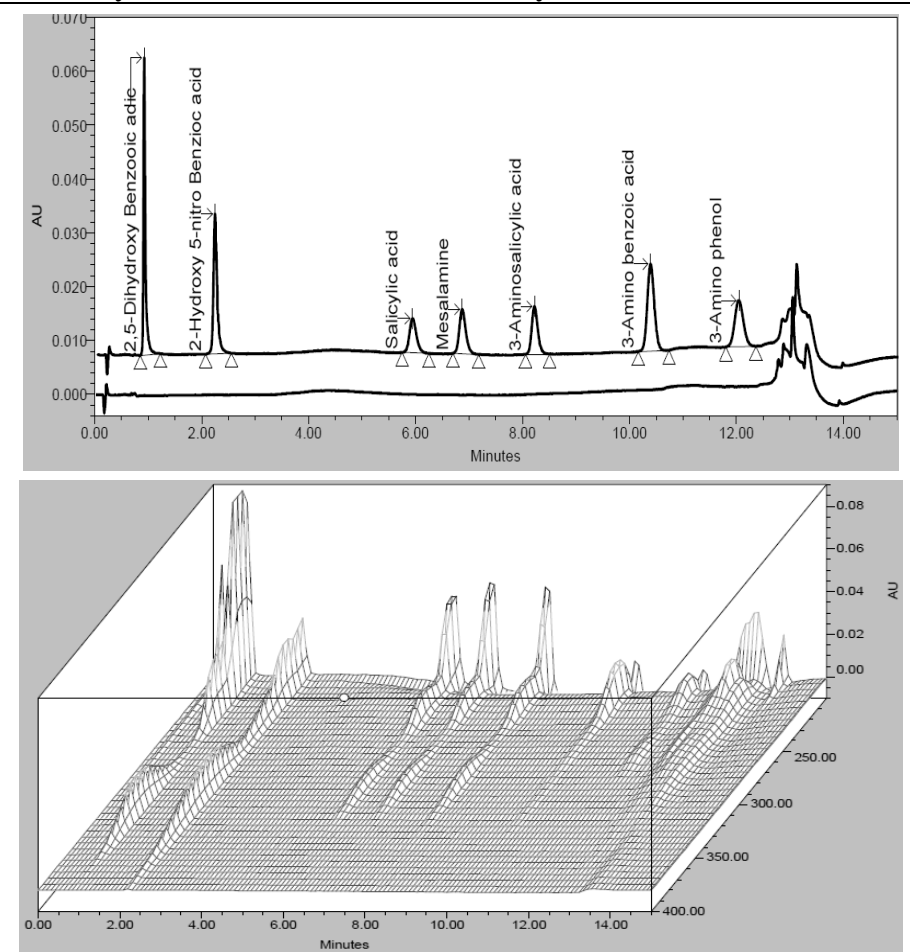

Figure 3. Overlay chromatograms of placebo (bottom) and spiked impurities (top) with its 3D plot

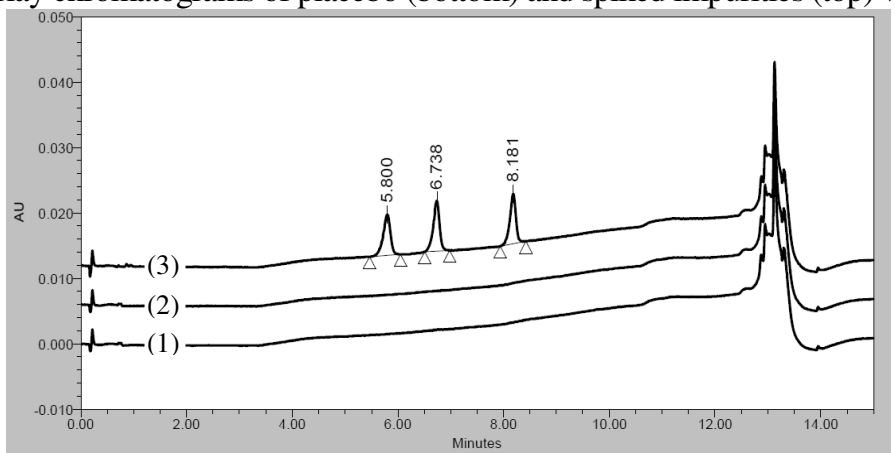

Figure 4. Overlay chromatograms of (1) blank; (2) placebo and (3) system suitability standard 

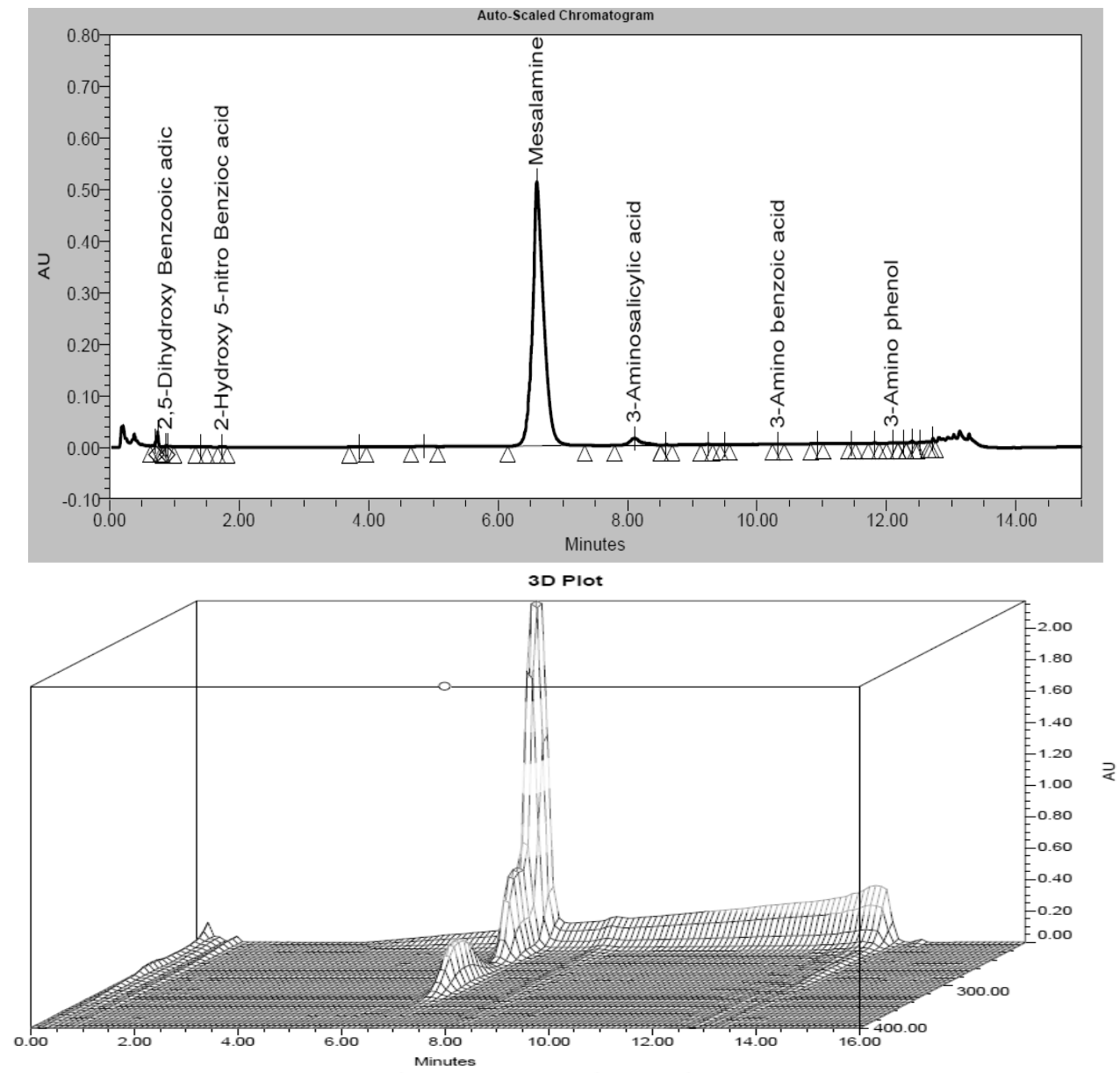

SampleName Base Degradation; Vial 2:E,4; Injection 1; Date Acquired 1/17/2010 5:56:24 PM

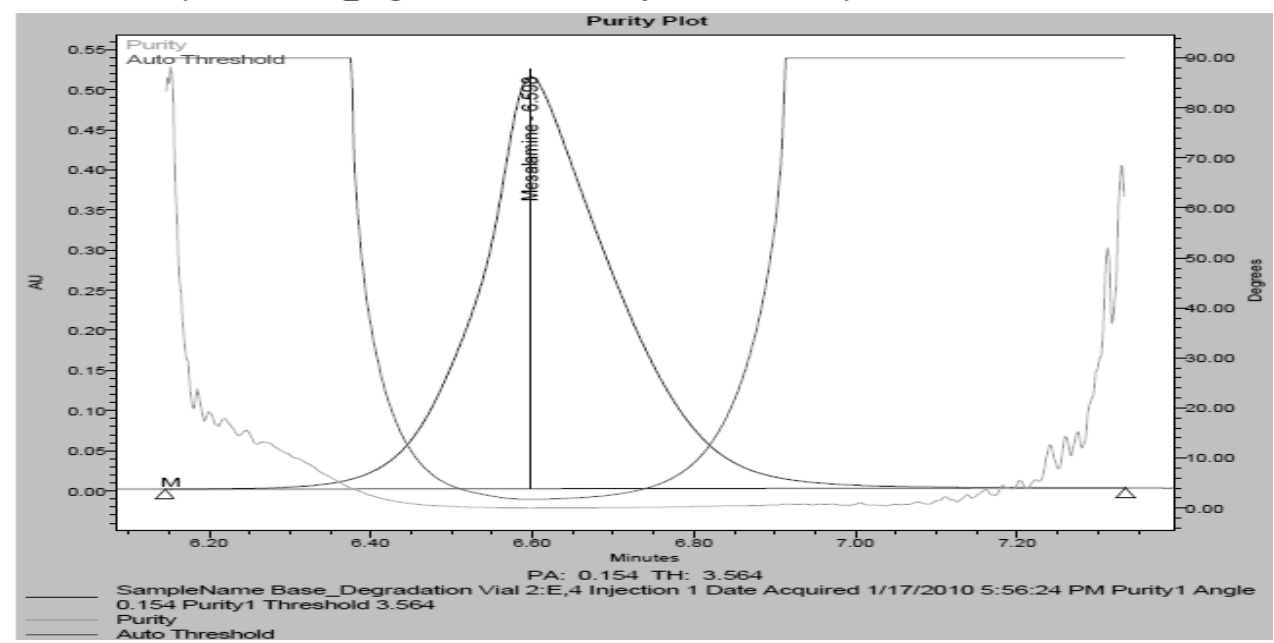

Figure 5. Chromatogram of alkali degraded tablet sample with its 3D plot and purity plot. 

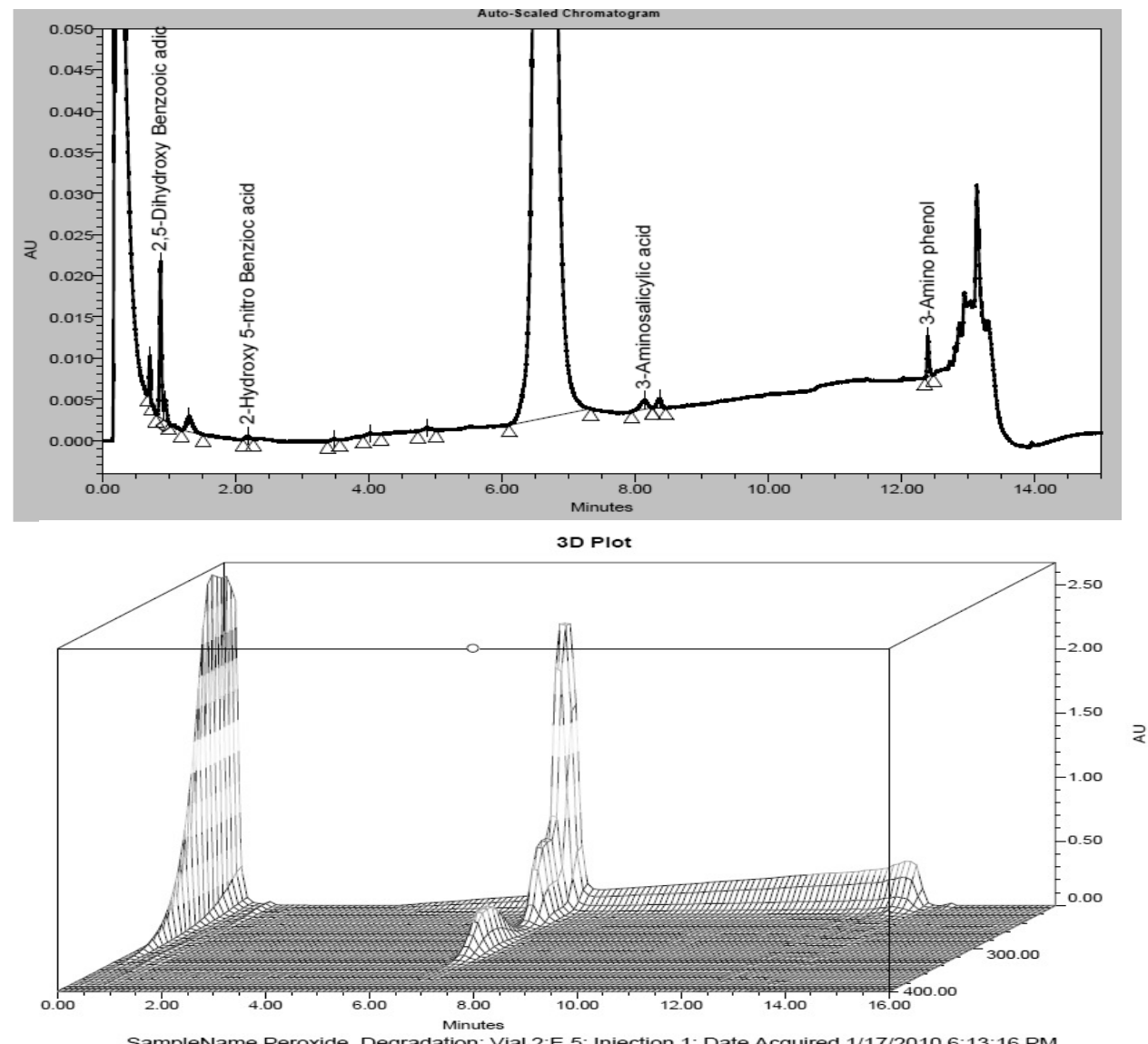

SampleName Peroxide_Degradation; Vial 2:E,5; Injection 1; Date Acquired 1/17/2010 6:13:16 PM

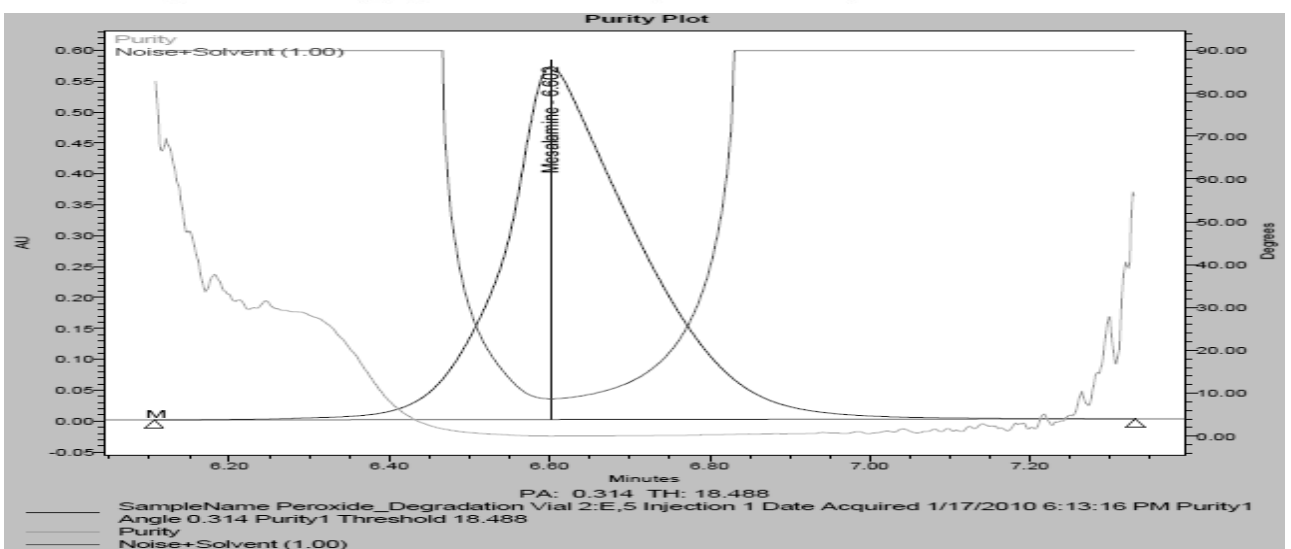

Figure 6.Chromatogram of peroxide degraded tablet sample with its 3D plot and purity plot.

Precision

Precision (at LOQ, 100\% and 150\%) results are shown in Table 5 along with intermediate precision data. Low values of RSD, indicates that the method is precise. Overlay chromatograms of precision at LOQ are presented in Figure 7. 
Table 5. Precision at three levels (LOQ, 100\% and 150\%) and intermediate precision results ${ }^{\S}$

\begin{tabular}{|c|c|c|c|c|c|c|c|c|}
\hline \multirow{3}{*}{ Impurities } & \multicolumn{2}{|c|}{ Precision at LOQ } & \multicolumn{2}{|c|}{ Precision at $100 \%$} & \multicolumn{2}{|c|}{ Precision at $150 \%$} & \multicolumn{2}{|c|}{$\begin{array}{l}\text { Intermediate } \\
\text { Precision }\end{array}$} \\
\hline & $\%$ & $\%$ & $\%$ & $\%$ & $\%$ & $\%$ & $\%$ & $\%$ \\
\hline & imp." & RSD* & imp." & RSD* & imp." & RSD* & imp." & RSD* \\
\hline Imp-A & 0.005 & 1.68 & 0.204 & 0.40 & 0.293 & 0.31 & 0.207 & 0.26 \\
\hline Imp-B & 0.005 & 1.59 & 0.206 & 0.06 & 0.301 & 0.41 & 0.203 & 0.43 \\
\hline Imp-C & 0.018 & 1.63 & 0.196 & 0.14 & 0.309 & 0.92 & 0.208 & 0.75 \\
\hline Imp-D & 0.019 & 1.78 & 0.200 & 1.22 & 0.295 & 0.88 & 0.212 & 0.50 \\
\hline Imp-E & 0.020 & 0.50 & 0.208 & 0.28 & 0.311 & 0.49 & 0.200 & 0.43 \\
\hline Imp-F & 0.018 & 0.38 & 0.202 & 0.74 & 0.281 & 1.48 & 0.180 & 0.47 \\
\hline
\end{tabular}

\# Average of six determinations; * Determined on six values

${ }^{\S}$ Demonstrated by spiking known impurities into sample

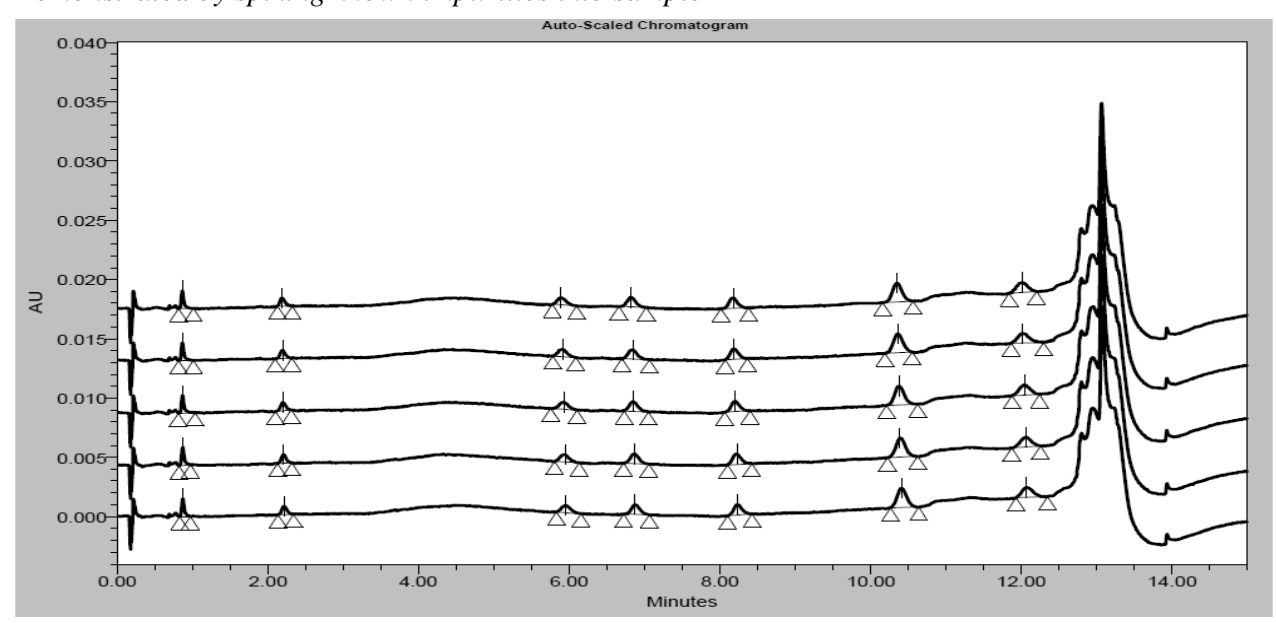

Figure 7. Overlay chromatograms of precision at LOQ level

Accuracy by recovery

The amount recovered was within $\pm 10 \%$ of amount added, which indicates that the method is accurate and also there is no interference due to excipients present in tablets. The results of recoveries for 5-ASA and impurities are shown in Table 6. Overlay chromatograms of accuracy are presented in Figure 8.

Table 6. Accuracy results

\begin{tabular}{ccccc}
\hline \multirow{2}{*}{ Substances } & \multicolumn{4}{c}{ Mean \% } \\
\cline { 2 - 4 } & at LOQ & at $50 \%^{\#}$ & at $100 \%^{\#}$ & at $150 \%^{\#}$ \\
\hline Imp-A & 105.5 & 102.1 & 100.8 & 98.9 \\
Imp-B & 102.4 & 101.5 & 99.4 & 101.1 \\
Imp-C & 97.4 & 98.5 & 101.3 & 103.2 \\
5-ASA & 95.9 & 99.5 & 102.7 & 99.5 \\
Imp-D & 104.3 & 100.3 & 101.5 & 98.7 \\
Imp-E & 101.1 & 98.6 & 101.2 & 99.1 \\
Imp-F & 103.9 & 97.9 & 102.6 & 100.6 \\
\hline
\end{tabular}

${ }^{\#}$ Average of three determinations 


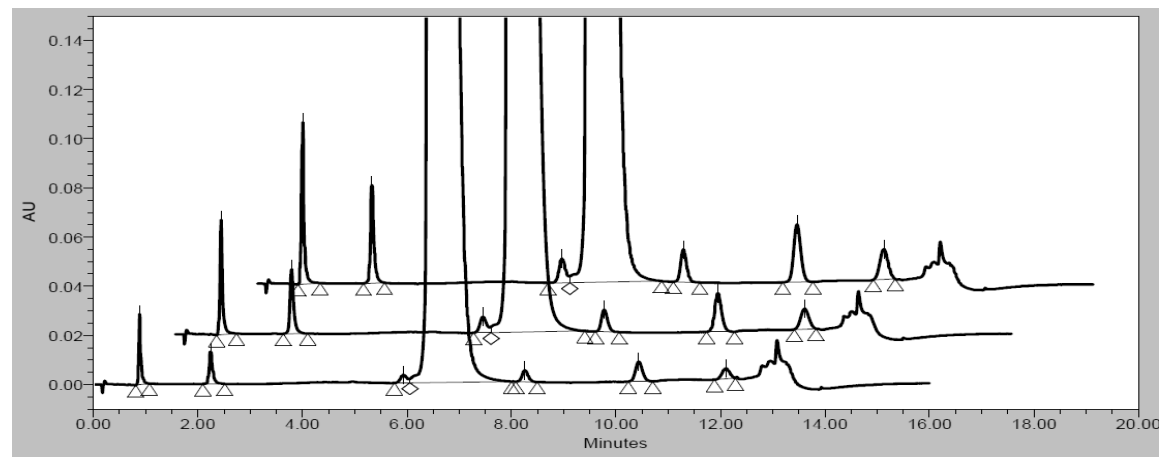

Figure 8. Overlay chromatograms of accuracy (at 50\%, 100\% and 150\%)

\section{$L O D$ and $L O Q$}

The concentration (in \%) with signal to noise ratio of at least 3 was taken as LOD and concentration with signal to noise of at least 10 was taken as LOQ, which meets the criteria defined by ICH guidelines ${ }^{39,40}$. The LOD and LOQ results of all substances are presented in Table 7. Precision result at LOQ was also presented in Table 5.

Table 7. Limit of detection and limit of quantification

\begin{tabular}{ccccc}
\hline \multirow{2}{*}{ Substances } & \multicolumn{2}{c}{ In \% (w.r.t. working conc.) } & \multicolumn{2}{c}{ Signal to noise ratio } \\
\cline { 2 - 5 } & LOD & LOQ & LOD & LOQ \\
\hline Imp-A & 0.0018 & 0.006 & 2.9 & 10.4 \\
Imp-B & 0.0018 & 0.006 & 3.2 & 10.0 \\
Imp-C & 0.006 & 0.020 & 2.7 & 10.0 \\
5-ASA & 0.006 & 0.020 & 2.4 & 9.7 \\
Imp-D & 0.006 & 0.020 & 3.0 & 9.9 \\
Imp-E & 0.006 & 0.020 & 3.3 & 13.5 \\
Imp-F & 0.006 & 0.020 & 3.1 & 10.2 \\
\hline
\end{tabular}

\section{Linearity}

The response was found linear for all substances from LOQ to $250 \%$ of working concentration. This test was performed on seven different levels of each substance, which gave us a good confidence on analytical method with respect to linear range. For the all substances correlation coefficient was greater than 0.999. Correlation coefficients, Yintercept bias and linearity equations for mesalamine and impurities are presented in Table 8. Overlay chromatograms of different linearity levels are also presented in Figure 9.

Table 8. Linearity results for 5-ASA and impurities

\begin{tabular}{ccccc}
\hline Compound & $\begin{array}{c}\text { Linearity } \\
\text { range, } \mu \mathrm{g} / \mathrm{mL}\end{array}$ & $\begin{array}{c}\text { Correlation } \\
\text { coefficient }\left(\mathrm{r}^{2}\right)\end{array}$ & Linearity (Equation) & $\begin{array}{c}\text { Y- Intercept } \\
\text { bias }\end{array}$ \\
\hline Imp-A & 0.096 to 8.00 & 0.9996 & $\mathrm{y}=44871(\mathrm{x})-2380$ & -1.692 \\
Imp-B & 0.096 to 8.00 & 0.9998 & $\mathrm{y}=40980(\mathrm{x})-1678.8$ & -1.301 \\
Imp-C & 0.32 to 8.00 & 0.9998 & $\mathrm{y}=18233(\mathrm{x})-711.35$ & -1.223 \\
5-ASA & 0.32 to 8.00 & 0.9997 & $\mathrm{y}=22128(\mathrm{x})-1366.6$ & -1.964 \\
Imp-D & 0.32 to 8.00 & 0.9997 & $\mathrm{y}=21633(\mathrm{x})+129.75$ & 0.186 \\
Imp-E & 0.32 to 8.00 & 0.9999 & $\mathrm{y}=46186(\mathrm{x})-624.15$ & -0.421 \\
Imp-F & 0.32 to 8.00 & 0.9997 & $\mathrm{y}=30622(\mathrm{x})-1182.2$ & -1.212 \\
\hline
\end{tabular}




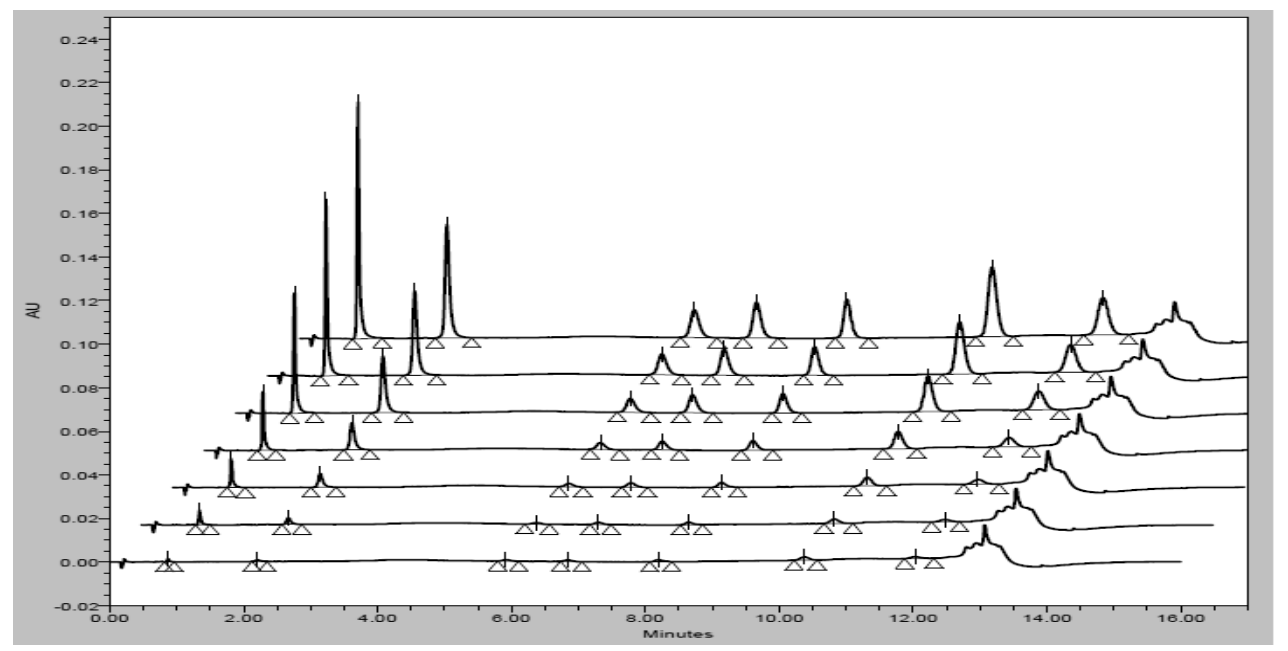

Figure 9. Overlay chromatograms of linearity study from LOQ to $250 \%$

\section{Robustness}

No significant effect was observed on system suitability parameters such as resolution, theoretical plates, tailing factor, similarity factor and RSD of respective components, when small but deliberate changes were made to chromatographic conditions. The results are presented in Table 3 along with system suitability parameters of normal methodology. No significant effect was observed on related retention time (RRT) of all impurities, when deliberate changes were made to chromatographic conditions. The impurities RRT variation results are presented and compared with normal methodology result, which was presented in Table 9. Thus, the method was found to be robust with respect to variability in variable conditions

Table 9. Robustness results

\begin{tabular}{|c|c|c|c|c|c|c|c|}
\hline \multirow{3}{*}{ Compound } & \multicolumn{7}{|c|}{ Related retention time of Impurities } \\
\hline & \multirow[t]{2}{*}{ Initial } & \multicolumn{2}{|c|}{$\begin{array}{c}\text { Flow rate per } \\
\text { minutes }\end{array}$} & \multicolumn{2}{|c|}{$\begin{array}{l}\text { Column oven } \\
\text { temperature }\end{array}$} & \multicolumn{2}{|c|}{$\begin{array}{l}\text { M.P.-A pH } \\
\text { variation }\end{array}$} \\
\hline & & $0.65 \mathrm{~mL}$ & $0.75 \mathrm{~mL}$ & $38^{\circ} \mathrm{C}$ & $42^{\circ} \mathrm{C}$ & $\mathrm{pH} 2.1$ & $\mathrm{pH} 2.3$ \\
\hline Imp-A & 0.134 & 0.139 & 0.139 & 0.139 & 0.139 & 0.139 & 0.139 \\
\hline Imp-B & 0.334 & 0.348 & 0.348 & 0.348 & 0.348 & 0.349 & 0.348 \\
\hline Imp-C & 0.914 & 0.915 & 0.915 & 0.915 & 0.914 & 0.914 & 0.914 \\
\hline 5-ASA & 1.000 & 1.000 & 1.000 & 1.000 & 1.000 & 1.000 & 1.000 \\
\hline Imp-D & 1.320 & 1.302 & 1.302 & 1.302 & 1.303 & 1.302 & 1.302 \\
\hline Imp-E & 1.666 & 1.631 & 1.631 & 1.631 & 1.634 & 1.632 & 1.634 \\
\hline Imp-F & 1.904 & 1.855 & 1.855 & 1.854 & 1.859 & 1.856 & 1.858 \\
\hline
\end{tabular}

\section{Stability of standard and sample solution}

Solution stability was performed and determined with duplicate spike sample preparation. Percentage difference in all impurities was calculated with respect to freshly injected sample solution. Sample solution did not show any appreciable change in all impurities value when stored at ambient temperature up to 24 hours, which was presented in Table 10. Standard solution did not show any unknown peak during this $24 \mathrm{~h}$ study and also full fill the requirement of \% RSD, which was also presented in Table 11. 
Table 10. Solution stability results (test preparation)

\begin{tabular}{ccccccccccc}
\hline & \multicolumn{3}{c}{ Initial sample } & \multicolumn{3}{c}{ Sample after 12 hours } & \multicolumn{3}{c}{ Sample after 24 hours } \\
\cline { 2 - 12 } Impurity & \multicolumn{2}{c}{ Imp. in \% } & \multicolumn{2}{c}{ Imp. in \% } & \multicolumn{1}{c}{ Difference in \% } & \multicolumn{2}{c}{ Imp. in \% } & \multicolumn{2}{c}{ Difference in \% } \\
\cline { 2 - 12 } & Sam-1 & Sam-2 & Sam-1 & Sam-2 & Sam-1 & Sam-2 & Sam-1 & Sam-2 & Sam-1 & Sam-2 \\
\hline Imp-A & 0.207 & 0.208 & 0.205 & 0.204 & 0.002 & 0.004 & 0.204 & 0.206 & 0.003 & 0.002 \\
Imp-B & 0.210 & 0.210 & 0.206 & 0.207 & 0.004 & 0.003 & 0.207 & 0.206 & 0.003 & 0.004 \\
Imp-C & 0.200 & 0.200 & 0.203 & 0.204 & 0.003 & 0.004 & 0.209 & 0.208 & 0.009 & 0.008 \\
Imp-D & 0.207 & 0.205 & 0.210 & 0.210 & 0.003 & 0.005 & 0.205 & 0.208 & 0.002 & 0.003 \\
Imp-E & 0.212 & 0.212 & 0.208 & 0.209 & 0.004 & 0.003 & 0.210 & 0.209 & 0.002 & 0.003 \\
Imp-F & 0.204 & 0.206 & 0.205 & 0.205 & 0.001 & 0.001 & 0.203 & 0.205 & 0.001 & 0.001 \\
\hline
\end{tabular}

Table 11. Solution stability results (standard preparation)

\begin{tabular}{ccccccc}
\hline \multirow{2}{*}{ Compound } & \multicolumn{2}{c}{ Initial } & \multicolumn{2}{c}{ After $12 \mathrm{~h}$} & \multicolumn{2}{c}{ After 24 h } \\
\cline { 2 - 7 } & Area & $\%$ RSD $^{\#}$ & Area & $\%$ RSD $^{\S}$ & Area & $\%$ RSD $^{*}$ \\
\hline Mesalamine & 66552.8 & 0.60 & 66710.8 & 0.79 & 66766.4 & 0.75 \\
\hline
\end{tabular}

${ }^{\#}$ Determined on five replicate injections

${ }^{\S}$ Determined on five initial and $12 \mathrm{~h}$ standard injections (RSD of six Inj.)

*Determined on five initial, one $12 \mathrm{~h}$ and one $24 \mathrm{~h}$ standard injections (RSD of seven Inj.)

\section{Filter compatibility}

Filter compatibility with $0.2 \mu \mathrm{m}$ syringe filter of PVDF and nylon filter was determined with duplicate sample preparation. Filtered sample solution was not shown any significant changes in impurities percentage with respect to centrifuge samples impurities percentage. Difference in all impurities percentage results was presented in Table 12. In displayed result difference in $\%$ of impurities was not observed more than $0.002 \%$, which indicates that both syringe filters are having good compatibility with sample solution.

Table 12. Filter compatibility results

\begin{tabular}{cccccccccccc}
\hline & \multicolumn{3}{c}{ Centrifuged } & \multicolumn{3}{c}{$\begin{array}{c}\text { PVDF Syringe filter } 0.2 \mu \\
\text { (Millipore) }\end{array}$} & \multicolumn{4}{c}{$\begin{array}{c}\text { Nylon Syringe filter } 0.2 \mu \\
\text { (Pall Life Sciences) }\end{array}$} \\
\cline { 2 - 13 } Impurity & \multicolumn{3}{c}{ Imp. in \% } & \multicolumn{4}{c}{ Imp. in \% } & Difference in \% & Imp. in \% & \multicolumn{2}{c}{ Difference in \% } \\
\cline { 2 - 13 } & Sam-1 & Sam-2 & Sam-1 & Sam-2 & Sam-1 & Sam-2 & Sam-1 & Sam-2 & Sam-1 & Sam-2 \\
\hline Imp-A & 0.205 & 0.204 & 0.205 & 0.205 & 0.000 & 0.001 & 0.206 & 0.205 & 0.001 & 0.001 \\
Imp-B & 0.206 & 0.207 & 0.207 & 0.206 & 0.001 & 0.001 & 0.206 & 0.205 & 0.000 & 0.002 \\
Imp-C & 0.203 & 0.204 & 0.203 & 0.204 & 0.000 & 0.000 & 0.203 & 0.204 & 0.000 & 0.000 \\
Imp-D & 0.210 & 0.210 & 0.209 & 0.212 & 0.001 & 0.002 & 0.210 & 0.210 & 0.000 & 0.000 \\
Imp-E & 0.208 & 0.209 & 0.210 & 0.209 & 0.002 & 0.000 & 0.210 & 0.209 & 0.002 & 0.000 \\
Imp-F & 0.205 & 0.205 & 0.203 & 0.204 & 0.002 & 0.001 & 0.205 & 0.205 & 0.000 & 0.000 \\
\hline
\end{tabular}

\section{Conclusion}

A novel RP-UPLC method was successfully developed and validated for simultaneous determination of all six impurities from mesalamine delayed-release formulation. The total run time was 15 minutes, within which drug and their impurities/degradation products were well separated from each other. Method validation results have proved that the method is selective, precise, accurate, linear, rugged, robust and stability indicating with low LOD and LOQ. This method can be successfully applied for the routine analysis as well as stability 
study of mesalamine delayed-release drug product. Overall, the method provides high throughput solution for determination of all related impurities in mesalamine delayed-release formulation with excellent selectivity, precision and accuracy.

\section{Acknowledgment}

The authors would like to thank M/s. Dr. Reddy's Laboratories Ltd. for supporting this work. All raw data from the validation work archived at Dr. Reddy's Laboratories Ltd. All the development and validation work was performed at Analytical Research and Development (AR\&D) Lab., Dr. Reddy's Laboratory Ltd., IPDO, Bachupally, Hyderabad, India. The authors' Intellectual Property Management department (IPM) has given this manuscript internal publication number is PUB-00037-10.

\section{References}

1. Gisbert J P, Gomollon F, Mate J and Pajares J M, A systematic review., Dig Dis Sci 2002, 47, 471-488.

2. Klotz U, Maier K, Fisher C and Heinkel K, Eur J Clin Pharmacol., 2000, 56, 353-362.

3. De Vos M, Clin Pharmacokinet., 2000, 39, 85-97.

4. http://en.wikipedia.org/wiki/Mesalazine

5. Pappercorn M A and Goldman P, Gastroenterology, 1973, 64(2), 240-245.

6. Haagen Nielsen O and Bondesen S, Br J Clin Pharmacol., 1983, 16(6), 738-740.

7. $\quad$ Schröder H and Compbell D E, Clin Pharmacol Ther, 1972, 13(4), 539-551.

8. Goodman and Gilman's. The Pharmacological Basis of Therapeutics, $8^{\text {th }}$ Ed., Pergamon, 1990, p 650.

9. Reynolds J F, (Ed.) Martindale. The Extra Pharmacopoeia, Royal Pharmaceutical Society, London, 1996, p.1227.

10. Alekha K Dash and Harry G Brittain, Analytical Profile of Drug Substances and Excipients, 1998, 25, 209-242; doi: 10.1016/S0099-5428(08).

11. Rita K Palsmeier, Donna M Radzik and Craig E Lunte, Pharma Res., 1992, 9(7), 933-938.

12. Zhou S Y, Fleisher D, Pao L H, Li C, Winward B, Zimmermann E M, Drug Metab Dispos., 1999, 27(4), 479-485.

13. Liu Z C, McClelland R A and Uetrecht J P, Drug Metab Dispos., 1995, 23(2), 246-250.

14. Bystrowska B, Nowak J and Brandys J, J Pharma Biomed Anal., 2000, 22(2), 341-347.

15. Fischer C and Klotz U, J Chromatogr. 1979, 162(2), 237-243.

16. Palmbo G, Bucchi S, Primavera L, Palumbo P and Carlucci G, Biomed Chromatogr., 2005, 19(5), 350-354.

17. Elisabetta Paslorini, Marcello Locatelli, Patrizia Simoni, Giulia Roda, Enrico Roda and Aldo Roda, J Chromatogr B Analyt Technol Biomed Life Sci., 2008, 872(1-2), 99-106.

18. Fischer C, Maier K and Klotz U, J Chromatogr., 1981, 225(2), 498-503.

19. Beata Bystrowska, Jolanta Nowak and Jerzy Brandys, J Pharma Biomed Anal., 2000, 22(2), 341-347.

20. Nobilis M, Vybiralova Z, Sladkova K, Lisa M, Holcapek M and J Kvetina, J Chromatogr A, 2006, 1119(1-2), 299-308.

21. Lecompte S, Simard M, Gauthier G and Donato L Di, A sensitive HPLC Method for the Determination of Mesalamine and its Metabolite in human Plasma using Fluorescence Detection., Phoenix International Life Sciences., Montreal, PQ Canada, 2000; www.aapsj.org/abstracts/AM_2000/2596.htm 
22. Hussain F N, Ajjan R A, Moustafa M, Anderson J C and Riley S A, J Chromatogr B, 1998, 716(1-2), 257-266.

23. Palumbo G, Carlucci G, Mazzeo P, Frieri G, Pimpo MT, Fanini D, J Pharm Biomed Anal., 1995, 14(1-2), 175-180.

24. Predrag Novak, Predrag Tepes, Ines Fistric, Lgor Bratos and Vesna Gabelica, $J$ Pharma Biomed Anal., 2006, 40(5), 1268-1272.

25. Joan Jensen, Claus Cornett, Carl Erik Olsen, Jette Tjornelund and Steen Honore Hansen, Int J Pharma., 1992, 88(1-3), 177-187.

26. Tang J, Sharif O, Pai C and Silverman A L, Dig Dis Sci. 2010, 55(6),1696-1703.

27. Brian S. Kersten, Tom Catalano and Yury Rozenman, J Chromatogr A, 1991, 588(1-2), 187-193.

28. Haney P W, Dash A K, J Chromatogr A, 1997, 765(2), 233-239.

29. Arbad B R and Jadhav S M, Asian J Chem., 2000, 12(1), 294-296.

30. Majji Sunil, Srinivasa Rao K and Rao M E B, Analytical Chemistry, An Indian Journal, 2008, 7(7), 546-550.

31. Biljana Nigovi and Branimir Imuni, J Pharma Biomed Anal., 2003, 32(1), 169-174.

32. Lee Allen, Julie Weinberger and Robert Weinberger,.J Chromatogr A, 2004, 1053(1-2), 217-226.

33. Roberto Gotti, Romeo Pomponio, Carlo Bertucci and Vanni Cavrini, J Chromatogr A, 2001, 916(1-2), 175-183.

34. Janice Aparecida Rafael, jose Roberto Jabor, Rubia Casagrande, Sandra Regina Georgetti,Maria de Fatima Borin and Maria Jose Vieira Fonseca, Brazilian J Pharma Sci., 2007, 43(1), 97-103.

35. United States Pharmacopeia, USP32-NF27, p 2895.

36. United States Pharmacopeia, USP32-NF27, p 2897.

37. United States Pharmacopeia, USP32-NF27, p 2894.

38. British Pharmacopoeia, BP- 2010, p 1368.

39. ICH, Validation of Analytical Procedure, Text and Methodology Q2 (R1): International conference on Harmonization, IFPMA, Geneva, 2005.

40. ICH, Stability testing of New drug Substances and Product (Q1AR), International conference on Harmonization, IFPMA, Geneva, 2002.

41. Genotoxic and Carcinogenic Impurities in drug Substances and Products: Recommended approaches. FDA Center for Drug Evaluation and Research. Guidance for Industry (Draft), 3 December 2008.

42. Derek I Robinson, A review and Perspective Organic Process Research and Development, 2010, 14, 946-959. 


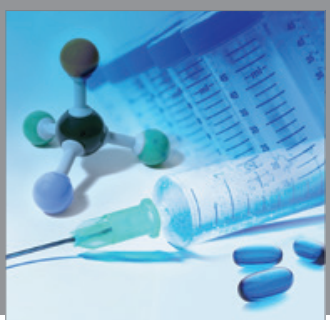

International Journal of

Medicinal Chemistry

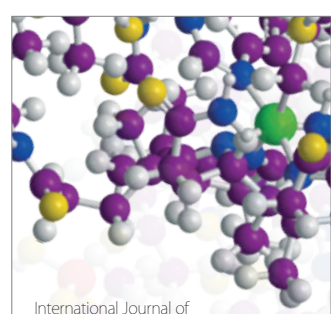

Carbohydrate Chemistry

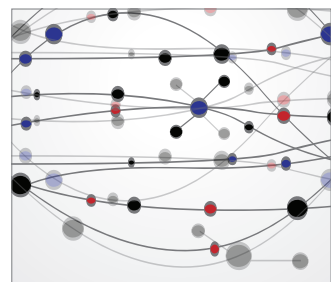

The Scientific World Journal
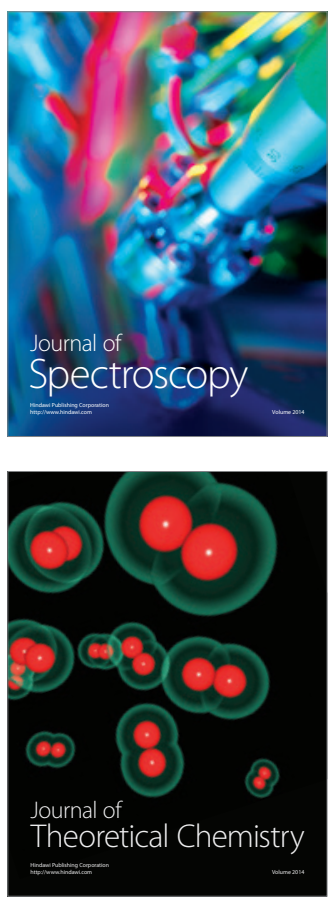
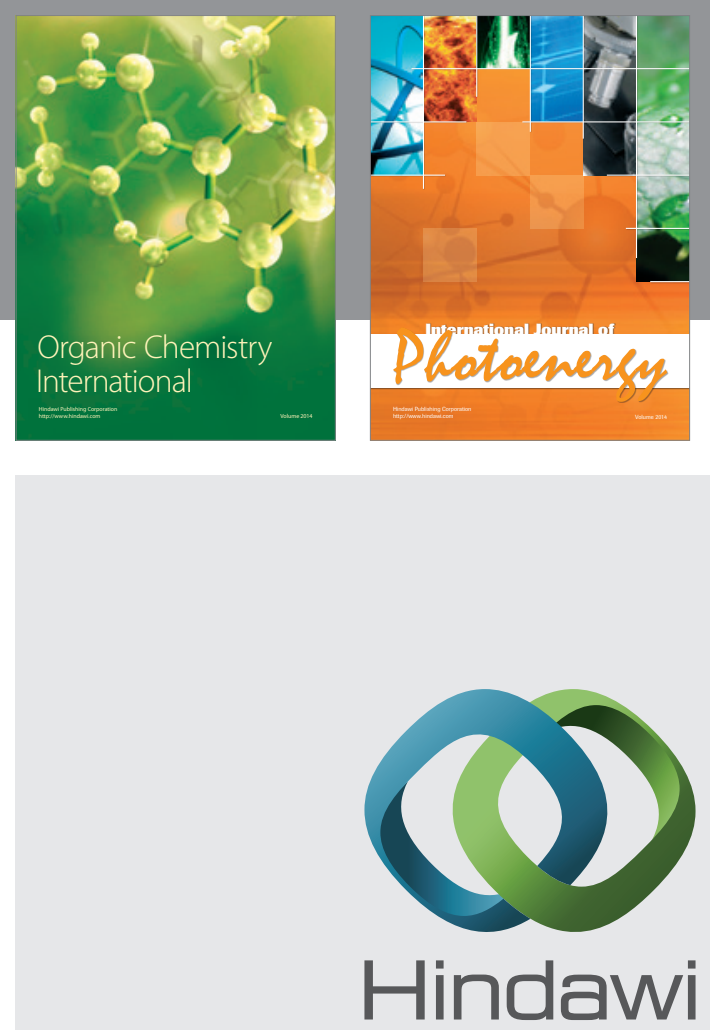

Submit your manuscripts at

http://www.hindawi.com
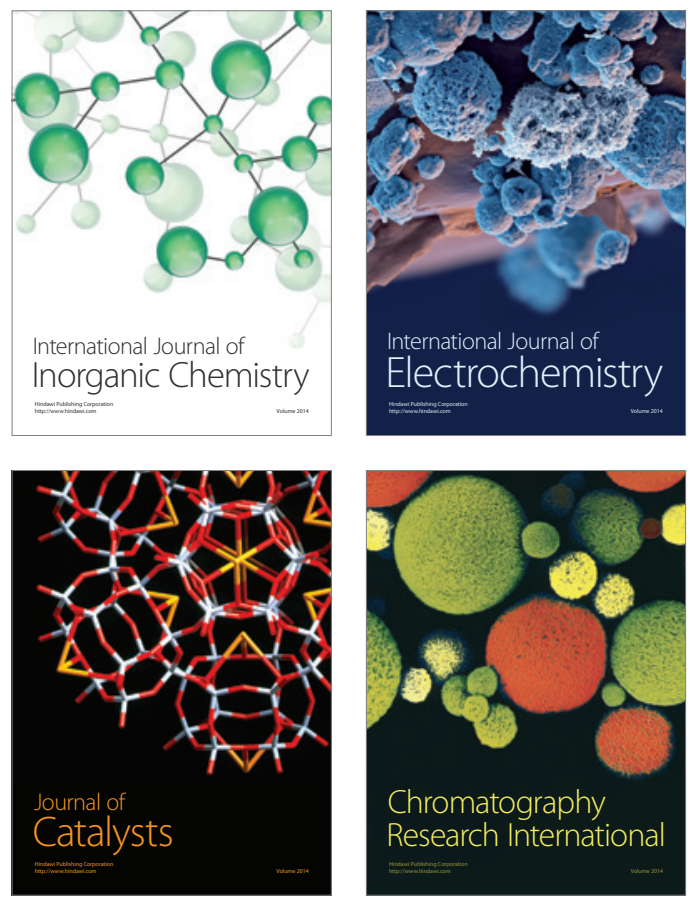
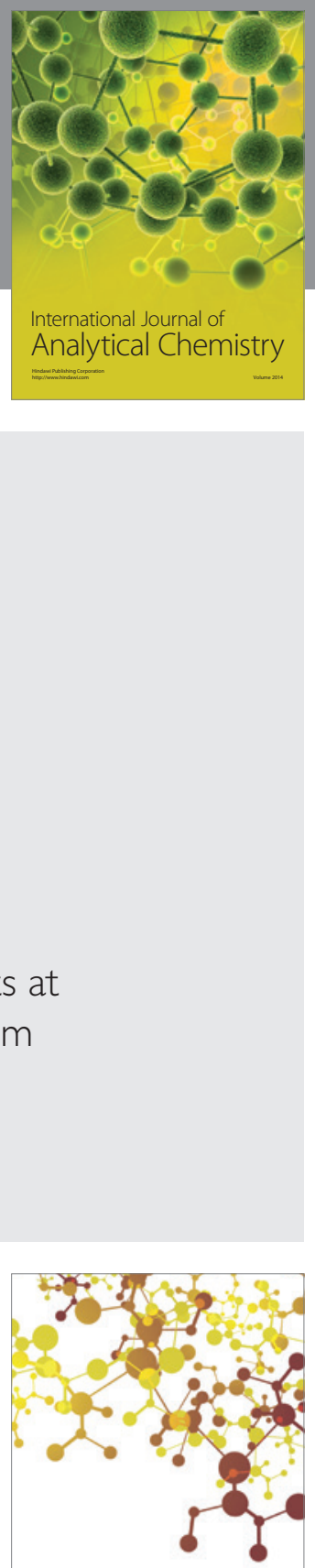

Journal of

Applied Chemistry
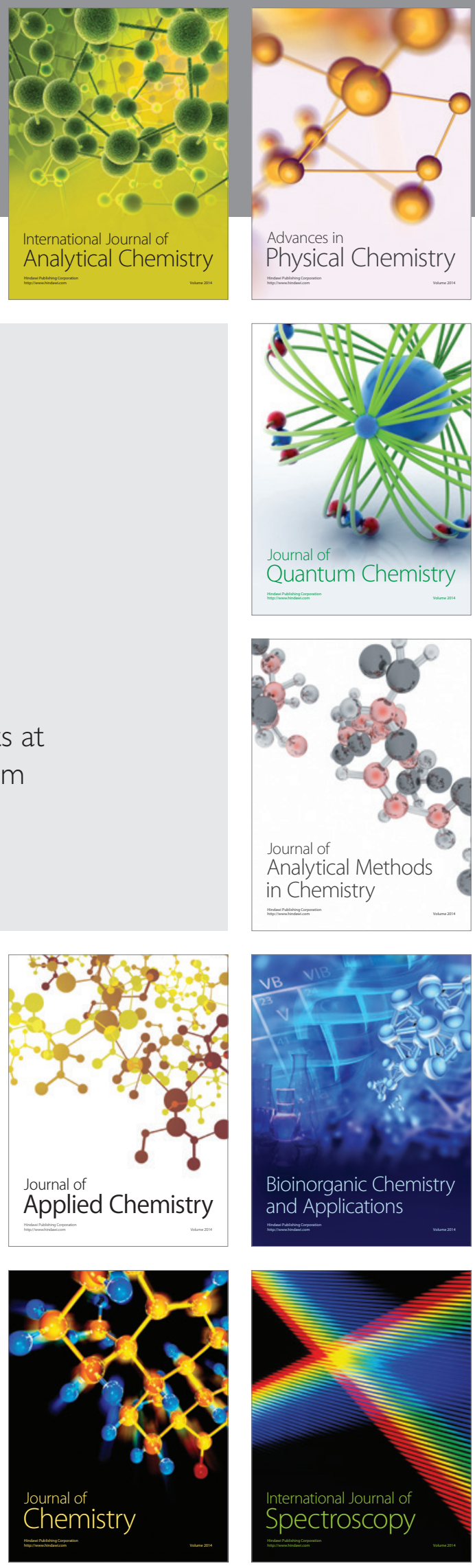